\title{
Associations of Sleep Problems with Asthma and Allergic Rhinitis Among Chinese Preschoolers: A Cross-Sectional Study
}

\section{Ying Ma ( $\square$ tianshidan918@163.com )}

Guangzhou Women and Children's Medical Center, Guangzhou Medical University

Jie Tang

Guangzhou Medical University

\section{Yuqi Wen}

Guangzhou Women and Children's Medical Center, Guangzhou Medical University

Yan Hu

Guangzhou Women and Children's Medical Center, Guangzhou Medical University

Jingjing Liang

Guangzhou Women and Children's Medical Center, Guangzhou Medical University

Lin Jiang

Guangzhou Women and Children's Medical Center, Guangzhou Medical University

Yanfei Xing

Guangzhou Women and Children's Medical Center, Guangzhou Medical University

Yanyan Song

Guangzhou Women and Children's Medical Center, Guangzhou Medical University

\section{Research Article}

Keywords: Sleep problems, Asthma, Allergic rhinitis, preschooler

Posted Date: December 16th, 2021

DOI: https://doi.org/10.21203/rs.3.rs-1139610/v1

License: (c) (i) This work is licensed under a Creative Commons Attribution 4.0 International License. Read Full License 


\section{Abstract \\ Background}

The aim of this study was to examine the associations of sleep problems with asthma and allergic rhinitis among Chinese preschoolers.

\section{Methods}

This cross-sectional survey was conducted in Guangzhou, China. Children aged 3-6 years were selected from 32 kindergartens in 7 regions. Asthma, allergic rhinitis and sleep problem were evaluated by a valid questionnaire. Binary logistic regression models were employed to estimate the odds ratios (OR) and $95 \%$ confidence intervals $(\mathrm{Cl})$ for asthma and allergic rhinitis according to short sleep duration, late bedtime and frequent nocturnal awaking.

\section{Results}

We included 4876 preschool children. Of these, 182 (3.7\%) diagnosed as asthma, and 511 (10.5\%) diagnosed as allergic rhinitis. Frequent nocturnal awakening was associated with asthma and allergic rhinitis, adjusted OR were 1.49(95\% Cl: 1.05 2.13) and 1.59(95\%Cl: 1.27-1.99), respectively. Further subgroup analysis showed the association of frequent nocturnal awakening with asthma differed by gender. No significant associations of short duration and late bedtime with asthma/ and allergic rhinitis were identified.

\section{Conclusions}

Our data suggested that frequent nocturnal awakening was associated with asthma and allergic rhinitis, and the association of frequent nocturnal awakening with asthma differed by gender. Further studies are warranted to address the causal relationship between nocturnal awaking and asthma and allergic rhinitis.

\section{Introduction}

Allergic respiratory diseases (ARDs), primarily asthma and allergic rhinitis, are important clinical and public concerns all over the world. Globally, asthma and allergic rhinitis affect $4-10 \%$ and $10-30 \%$ of the whole population [1], respectively. Among children, the prevalence of ARDs is disparity across regions and countries, but the overall prevalence increases year by year [2-4]. ARDs not only increase health and care costs, but also reduce the life quality of suffers $[5,6]$, which, therefore calling for more preventive measures to minimize its detriment fundamentally.

ARDs are associated with a broad range of environmental factors and lifestyles other than genetic factors [7], which are not fully understood. Recently, associations between sleep problems and ARDs have gained increasing attention. Sleep problems, such as difficulty in settling to sleep, nocturnal awakening, and irregular sleep patterns and short-duration sleep, are common in children. Approximately $25 \%$ of children experience some forms of sleep problem during childhood [8]. To date, several studies have examined the association between sleep problems and ARDs. However, there were few studies have been conducted among preschool age children $[9,10]$. In addition, previous studies have suggested that residency in urban areas and prenatal smoking and passive smoking are associated with an increased risk of wheeze and asthma [11-13], however, no study that examined the association between sleep problems and ARDs has adjusted for such confounders. Therefore, the association of sleep problems with asthma and allergic rhinitis among pre-school aged children remains unclear. To identify the association among pre-school age children is substantially important, since pre-school age a critical period for developing the physique and immune system and forming a healthy lifestyle, including developing good sleep habits [10, 14].

The present study aimed to examine the associations of sleep problems with asthma and allergic rhinitis among Chinese preschool children. We hypothesized that sleep problems, include frequent nocturnal awakening, short duration and late bedtime would be associated with ARDs even after adjustment for potential confounders. 


\section{Methods}

\section{Study design and participants}

We conducted a cross-sectional survey of children aged 3-6 years in Guangzhou between July to October in 2015, which was a part of the National Survey on Physical Growth and Development of Children in nine cities of China (NSPGDC) [15]. The NSPGDC used the identical methodology to collect data from nine cities, thus data collected in each city could be analyzed to produce a general conclusion for the local population. The study design, organization, and implementation of the NSPGDC have been published previously [16]. Briefly, in each study city, a cluster random sampling method based on age groups (there were 22 age groups and 150-200 subjects for each sex-age subgroup) for both urban and rural areas was employed to produce a random sample

[17]. Children under 3 years in a community was classified as a minimum cluster unit, and children aged 3 and above in kindergarten regarded as a unit. Exclusion criteria included temporary residents, acute illness within a month, chronic illness (such as cardiopathy, chronic nephrosis, tuberculosis, persistent hepatitis), obviously malnourished and physically handicapped.

The data of 3 to 6 years old children in Guangzhou of the survey was included in this analyze. 5102 participants aged 3 to 6 years were selected from 16 kindergartens in urban administrative districts (Yuexiu, Liwan and Haizhu), and 16 kindergartens in rural administrative districts (Conghua, Huadu, Panyu and Baiyun). We excluded 235 participants after reviewing the completeness of the questionnaire (with missing data $>15 \%$ ). Therefore, the remained 4867participants were included in the final analysis, with an effective response rate of $95.4 \%$ (4867/5102). Data was collected by local trained physicians with a structured questionnaire, which include participants' demographic characteristics, mother's health conditions during pregnancy, delivery mode, feeding patterns in the first 6 six months, sleep problems and ARDs of the participants. Body weight and height were also measured by calibrated instruments and standard specifications, and body mass index (BMI) was calculated by dividing the weight in $\mathrm{kg}$ by the square of length in $\mathrm{m}$. Age and sex specific BMI z-score was calculated according to the Chinese standard[18].

\section{Measurement}

Asthma and allergic rhinitis was assessed by the face to face interviewed questions based on the International Study of Asthma and Allergy in Children Questionnaire (ISAACQ) ("Has your baby had wheezing or whistling in the chest during the past 12 months?" "Has your baby had a problem with sneezing, or a runny, or a blocked nose when he/she did not have a cold or the flu during the past 12 months?" [19]. And we asked children's caregivers whether their children had been diagnosed with asthma/allergic rhinitis by doctors in the past 12 months, and whether their children had taken any aerosol inhalation medicine due to the asthma or wheeze? The pediatricians reviewed the questionnaire and made a judgment that children with symptoms of wheeze or whistling in the chest and had been diagnosed with asthma and use asthma medicine in recent 12 months would be defined as asthma, and the children with symptoms of sneezing, or a runny, or a blocked nose and had been diagnosed with allergic rhinitis would be defined as allergic rhinitis.

We assessed sleep duration, usual bedtime and nocturnal awakening frequency during recent two weeks in the present study, using the questions derived from the Chinese version of The Children's Sleep Habits Questionnaire (CSHQ) [20]. Sleep duration was assessed based on the questions ("Write in your child's usual amount of sleep each day (combining nighttime sleep and naps)." According to the National Sleep Foundation's recommendation, preschoolers (3-6years) who sleep less than 10 hours were defined as short sleep duration [21]. Bedtime was assesses by the question ("write in your child's usual bedtime"). As the 75 percentiles of bedtime among 3 to 6 aged children in this study was 22:00, the bedtime was classified into 2 groups: at or before 22:00 and after 22:00, and bedtime later than 22:00 was considered as a late bedtime. The nocturnal awakening frequency was assessed by the question ("write in your child's number of wake up times during the night"), and classified into 2 groups: none or seldom, and once or more per night. According to the previous study by the National Sleep Foundation [19], children who wakened once or more per night among preschoolers (3-6 years) were defined as frequent nocturnal wakening.

Previous studies suggested a broad range of demographic characteristic and environmental factors that are associated with Asthma and allergic rhinitis $[9,10,22,23]$. Therefore, we adjusted for these potential confounders, which was distributed differently according to the allergic disease in our analysis, including resident area, age, gender, mother's education, BMI z-score of children, delivery mode, birth weight, maternal tobacco exposure during pregnancy, feeding patterns in the first 6 months. 


\section{Ethics declarations}

The study was approved by the Ethical Committee for Biomedical Research in Guangzhou Women and Children's Medical Center, and was conducted in accordance with Helsinki

Declaration and Ethical Guidelines for Research Involving Human Participants. A written informed consent was obtained from all the participants' parents before starting of the survey.

\section{Statistical analysis}

Mean and standard deviation were reported for continuous variables. Frequencies and percentage were reported for categorical variables. T tests and Chi-square tests were used for comparing continuous and categorical variables, respectively. Binary logistic regression models were employed to estimate the odds ratios (OR) and 95\% confidence intervals (Cl) for asthma and allergic rhinitis according to short sleep duration, late bedtime and frequent nocturnal awaking, respectively. In each logistic regression model, three models were fitted.

In model 1, we estimated the crude ORs. In model 2, we adjusted for demographic characteristics, included region (urban/rural), gender (boys/girls), age, mother's educational level (college or above/senior high school/junior high school or below) and BMI zscore In model 3, we additionally adjusted for delivery mode (vaginal delivery/cesarean delivery), birth weight ( $<2500 \mathrm{~g} / 2500$ $3900 \mathrm{~g} / \geq 4000 \mathrm{~g}$ ), maternal tobacco exposure (smoking or passive smoking) during pregnancy, feeding patterns in the first 6 months of the children (breastfeeding/artificial feeding/mixed feeding), passive smoking (yes/no) .We further conducted subgroup analysis to examine whether gender influence the associations of asthma and allergic rhinitis allergic rhinitis with frequent nocturnal awaking where significant associations were found. Missing data of continuous covariates was inputted based on means and categorical covariates was inputted by the median. Significance level was set at $P<0.05$ and all tests were 2-sided. Statistical analyses were conducted using SPSS Statistics, version 25.0 (IBM Corp).

\section{Results}

\section{Participants' characteristics}

We included 4867 children in the current analysis. Of them, 2518 (51.7\%) were boys and $2383(49.0 \%)$ were from the urban areas. The mean age of the participants was $4.28 \pm 1.05$ years. The other characteristics of the participants were summarized in Table 1. 
Table 1

The characteristics of the participants

\begin{tabular}{|c|c|c|c|c|c|c|}
\hline \multirow[t]{2}{*}{ Characteristics } & & \multirow{2}{*}{$\begin{array}{l}\text { Total } \\
(n=4867)\end{array}$} & \multicolumn{2}{|l|}{ Asthma } & \multicolumn{2}{|c|}{ Allergic rhinitis } \\
\hline & & & Yes(n=182) & No(n=4685) & Yes $(n=511)$ & No(n=4356) \\
\hline \multirow[t]{2}{*}{ Region } & Urban & 2383(49.0) & $103(56.6)$ * & $2280(48.7)$ & $283(55.4) *$ & $2100(48.2)$ \\
\hline & Rural & 2484(51.0) & $79(43.4)$ & 2405(51.3) & $228(44.6)$ & 2256(51.8) \\
\hline \multirow[t]{2}{*}{ Gender } & Boys & 2518(51.7) & $93(51.1)$ & 2425(51.8) & $300(58.7)$ * & $2218(50.9)$ \\
\hline & Girls & $2349(48.3)$ & $89(48.9)$ & $2260(48.2)$ & $211(41.3)$ & 2138(49.1) \\
\hline \multirow[t]{4}{*}{ Age } & 3 years & 1448(29.8) & $58(31.9)$ & 1390(29.7) & $124(24.3)^{*}$ & 1324(30.4) \\
\hline & 4 years & 1381(28.4) & $56(30.8)$ & 1325(28.3) & $144(28.2)$ & $1237(28.4)$ \\
\hline & 5 years & 1273(26.2) & $49(26.9)$ & 1224(26.1) & 161(31.5) & 1112(25.5) \\
\hline & 6 years & $765(15.7)$ & 19(10.4) & $746(15.9)$ & $82(16.0)$ & $683(15.7)$ \\
\hline \multirow[t]{2}{*}{ Ethnicity } & Han & 4767(97.9) & 178(97.8) & $4589(98.0)$ & $503(98.4)$ & 4264(97.9) \\
\hline & Others & $100(2.1)$ & $4(2.2)$ & $96(2.0)$ & $8(1.6)$ & $92(2.1)$ \\
\hline \multirow[t]{3}{*}{ Mother's educational level } & College or above & $3205(65.9)$ & 133(73.1) & $3072(65.6)$ & $374(73.2)$ * & $2831(65.0)$ \\
\hline & Senior high school & 1063(21.8) & 29(15.9) & 1034(22.1) & $83(16.2)$ & $980(22.5)$ \\
\hline & $\begin{array}{l}\text { Junior high school } \\
\text { or below }\end{array}$ & $599(12.3)$ & $20(11.0)$ & $579(12.4)$ & $54(10.6)$ & $545(12.5)$ \\
\hline \multirow[t]{4}{*}{ Mother's occupation } & Famers & $36(0.7)$ & $0(0)$ & $36(0.8)$ & $6(1.2)$ & $30(0.7)$ \\
\hline & Workers & 1467(30.1) & $65(35.7)$ & 1402(329.9) & $151(29.5)$ & 1316(30.2) \\
\hline & Servicer & $977(20.1)$ & $33(18.1)$ & $944(20.1)$ & $106(20.7)$ & $871(20.0)$ \\
\hline & Others & $2387(49.0)$ & $84(46.2)$ & 2303(49.2) & $248(48.5)$ & 2139(49.1) \\
\hline \multirow{4}{*}{$\begin{array}{l}\text { Family annual income } \\
\text { (RMB) }\end{array}$} & $<50000$ & $567(11.6)$ & $15(8.2)$ & $5523(11.8)$ & $58(11.4)$ & $509(11.7)$ \\
\hline & 100000 & 1262(25.9) & $46(25.3)$ & $1216(26.0)$ & $125(24.5)$ & 1137(26.1) \\
\hline & $\sim 300000$ & 2292(47.1) & $89(48.9)$ & 2203(47.0) & $263(51.5)$ & $2029(46.6)$ \\
\hline & $>300000$ & $746(15.3)$ & $32(17.6)$ & $714(15.2)$ & $65(12.7)$ & $681(15.6)$ \\
\hline \multirow[t]{2}{*}{ Delivery methods } & Vaginal delivery & 2587(53.2) & $94(51.6)$ & 2493(53.2) & $249(48.7)$ * & 2338(53.7) \\
\hline & Caesarean delivery & $2280(46.8)$ & $88(48.4)$ & 2192(46.8) & $262(51.3)$ & 2018(46.3) \\
\hline \multirow[t]{2}{*}{ Preterm birth } & Yes & 134(2.8) & $9(4.9)$ & $125(2.7)$ & 19(3.7) & 115(2.6) \\
\hline & No & 4733(97.2) & 173(95.1) & 4560(97.3) & 492(96.3) & 4241(97.4) \\
\hline \multirow[t]{3}{*}{ Birth weight (g) } & $<2500$ & $74(1.5)$ & $5(2.7) *$ & $69(1.5)$ & $9(1.8)$ & $65(1.5)$ \\
\hline & 2500-3999 & $4610(94.7)$ & 173(95.1) & $4437(94.7)$ & 489(95.7) & $4121(94.6)$ \\
\hline & $\geq 4000$ & 183(3.8) & $4(2.2)$ & 179(3.8) & $13(2.5)$ & 170(3.9) \\
\hline \multirow{3}{*}{$\begin{array}{l}\text { Feeding patterns in the first } \\
6 \text { months }\end{array}$} & Breastfeeding & 1585(32.6) & $45(24.7)$ & 1540(32.9) & $37(26.8) \star$ & 1448(33.2) \\
\hline & Artificial feeding & $873(17.9)$ & $33(18.17)$ & $840(17.9)$ & 101(19.8) & 772(17.7) \\
\hline & Mixed feeding & $2409(49.5)$ & 104(57.1) & 2305 (49.2) & $273(53.4)$ & $2136(49.0)$ \\
\hline $\begin{array}{l}\text { Maternal tobacco exposure } \\
\text { during pregnancy } \\
\star P<0.05\end{array}$ & Yes & 1694(34.8) & $76(41.8) *$ & 1618(34.5) & 194(38.0) & 1500(34.4) \\
\hline
\end{tabular}




\begin{tabular}{|c|c|c|c|c|c|c|}
\hline \multirow[t]{2}{*}{ Characteristics } & & \multirow{2}{*}{$\begin{array}{l}\text { Total } \\
(n=4867)\end{array}$} & \multicolumn{2}{|l|}{ Asthma } & \multicolumn{2}{|c|}{ Allergic rhinitis } \\
\hline & & & Yes(n=182) & No(n=4685) & Yes $(n=511)$ & No( $n=4356)$ \\
\hline \multirow{3}{*}{$\begin{array}{l}\text { Passive smoking of } \\
\text { Children }\end{array}$} & No & $3173(65.2)$ & $106(58.2)$ & $3067(65.5)$ & $317(62.0)$ & $2856(5.6)$ \\
\hline & Yes & 1969(40.5) & $82(45.1)$ & $1887(460.3)$ & $215(42.1)$ & $1754(40.3)$ \\
\hline & No & 2898(59.5) & $100(54.9)$ & 2798(59.7) & $296(57.9)$ & 2602(59.7) \\
\hline Children's BMI z-score & & $0.09 \pm 0.98$ & $0.14 \pm 0.97$ & $0.09 \pm 0.98$ & $0.03 \pm 0.92$ & $0.10 \pm 0.99$ \\
\hline$\star P<0.05$ & & & & & & \\
\hline
\end{tabular}

Overall, $182(3.7 \%)$ of the participants were diagnosed as asthma. Compared with the participants without asthma, participants with asthma were more likely to be living in urban areas having low birth weight and exposed to tobacco exposure during pregnancy. There were 511 (10.5\%) participants diagnosed as allergic rhinitis. Compared with participants without allergic rhinitis, those with allergic rhinitis were likely to be living in urban areas, boys, cesarean delivery, less breast-feeding and having higher maternal educational level (see Table 1).

\section{Association Between Sleep Problems And Asthma}

Of the 4867 children included, $292(6.0 \%)$ had a short sleep duration. Among the children who diagnosed as asthma, 10 (5.5\%) had a short sleep duration; while among the children without asthma, $282(6.0 \%)$ had a short sleep duration. No significant association between short sleep duration and asthma was found (Table 2). There were 976 (20.1\%) participants go to sleep after 22:00. Among the children who diagnosed as asthma or not, 41 (22.5\%) and $935(20.0 \%)$ had late bedtime, respectively. There was also no significant association between late bedtime and asthma (Table 2). There were816 (16.8\%) participants had frequent nocturnal awakenings, 42(23.1\%) participants diagnosed as asthma and 774 (16.5\%) participants without asthma had frequent nocturnal awakenings, significant association between frequent nocturnal awakenings and asthma was found (Table 2).

Table 2

Frequency and proportion of sleep problems by asthma and allergic rhinitis

\begin{tabular}{|c|c|c|c|c|c|c|c|c|c|}
\hline \multirow{2}{*}{$\begin{array}{l}\text { Sleep } \\
\text { problems }\end{array}$} & \multirow[t]{2}{*}{ Total(N=4867) } & \multicolumn{2}{|c|}{ Asthma (n/\%) } & \multirow[t]{2}{*}{$x^{2}$} & \multirow[t]{2}{*}{$P$} & \multicolumn{2}{|c|}{ Allergic rhinitis (n/\%) } & \multirow[t]{2}{*}{$\chi^{2}$} & \multirow[t]{2}{*}{$P$} \\
\hline & & $\operatorname{Yes}(\mathrm{N}=182)$ & $\mathrm{No}(\mathrm{N}=4685)$ & & & Yes $(\mathrm{N}=511)$ & $\mathrm{No}(\mathrm{N}=4356)$ & & \\
\hline \multicolumn{10}{|c|}{ Short Sleep duration } \\
\hline No & $4575(94.0)$ & 172(94.5) & $44.3(94.0)$ & 0.09 & 0.77 & $470(92.0)$ & $4105(94.2)$ & 4.15 & 0.04 \\
\hline Yes & 292(6.0) & $10(5.5)$ & $282(6.0)$ & & & $41(8.0)$ & $251(5.8)$ & & \\
\hline \multicolumn{10}{|c|}{ Late bedtime } \\
\hline No & $3891(19.9)$ & $141(77.5)$ & $3750(80.0)$ & 0.72 & 0.40 & $391(76.5)$ & $3500(80.3)$ & 4.19 & 0.04 \\
\hline Yes & $976(20.1)$ & $41(22.5)$ & $935(20.0)$ & & & $120(23.5)$ & $856(19.7)$ & & \\
\hline \multicolumn{10}{|c|}{ Frequent Nocturnal awaking } \\
\hline No & $4051(83.2)$ & $140(76.9)$ & $3911(83.5)$ & 5.40 & 0.02 & $395(77.3)$ & $3656(83.9)$ & 14.41 & $<0.001$ \\
\hline Yes & $816(16.8)$ & $42(23.1)$ & 774(16.5) & & & $116(22.7)$ & $700(16.1)$ & & \\
\hline
\end{tabular}

The unadjusted and adjusted ORs for asthma for sleep problems were showed in Table 3. From model 1 to model 3, the ORs were not change substantially. In the fully adjusted models, significant association was only found between frequent nocturnal awakenings and asthma, the OR was $1.49(95 \% \mathrm{Cl}$ : 1.05 2.13). Further subgroup analysis showed that significant association between frequent nocturnal awakenings and asthma was found among girls but not among boys (Table 4). 
Table 3

Association of sleep problems with asthma or allergic rhinitis among per-school children

\begin{tabular}{|c|c|c|c|c|c|c|}
\hline & Model $1^{\text {a }}$ & $P$ & Model $2^{b}$ & $P$ & Model $3^{c}$ & $P$ \\
\hline & OR (95\%Cl) & & OR (95\%Cl) & & OR (95\%Cl) & \\
\hline Slee & & & & & & \\
\hline Sho & & & & & & \\
\hline No & 1(Ref) & & 1(Ref) & & 1(Ref) & \\
\hline Yes & $0.91(0.47-1.74)$ & 0.770 & $0.98(0.50-1.89)$ & 0.940 & $0.95(0.49-1.84)$ & 0.867 \\
\hline Late & & & & & & \\
\hline No & 1(Ref) & & 1(Ref) & & 1(Ref) & \\
\hline Yes & $1.17(0.82-1.66)$ & 0.396 & $1.12(0.78-1.60)$ & 0.535 & $1.11(0.78-1.58)$ & 0.574 \\
\hline Freq & & & & & & \\
\hline No & 1(Ref) & & 1(Ref) & & 1(Ref) & \\
\hline Yes & $1.52(1.07-2.16)$ & 0.021 & $1.50(1.05-2.13)$ & 0.026 & $1.49(1.05-2.13)$ & 0.028 \\
\hline Slee & chinitis & & & & & \\
\hline Sho & & & & & & \\
\hline No & 1(Ref) & & 1(Ref) & & 1(Ref) & \\
\hline Yes & $1.43(1.01-2.01)$ & 0.043 & $1.26(0.89-1.80)$ & 0.197 & $1.23(0.86-1.76)$ & 0.247 \\
\hline Late & & & & & & \\
\hline No & 1(Ref) & & 1(Ref) & & 1(Ref) & \\
\hline Yes & $1.26(1.01-1.56)$ & 0.041 & $1.25(1.01-1.56)$ & 0.045 & $1.24(0.99-1.54)$ & 0.056 \\
\hline Freq & & & & & & \\
\hline No & 1(Ref) & & 1(Ref) & & 1(Ref) & \\
\hline Yes & $1.53(1.23-1.91)$ & $<0.001$ & $1.59(1.27-1.99)$ & $<0.001$ & $1.59(1.27-1.99)$ & $<0.001$ \\
\hline a M & & & & & & \\
\hline & on, gender, age, $\mathrm{m}$ & r's educa & ial level, and BMI & ore. & & \\
\hline
\end{tabular}


Table 4

Association between frequent nocturnal awaking and asthma according to gender

\begin{tabular}{|c|c|c|c|c|c|}
\hline \multirow[t]{2}{*}{ Frequent nocturnal awaking } & \multirow[t]{2}{*}{ No. of asthma } & Model 1 a & \multirow[t]{2}{*}{$P$} & Model $2^{b}$ & \multirow[t]{2}{*}{$P$} \\
\hline & & OR $(95 \% \mathrm{Cl})$ & & OR $(95 \% \mathrm{Cl})$ & \\
\hline \multicolumn{6}{|l|}{ boy } \\
\hline No $(N=2086)$ & $73(3.5)$ & 1 (Ref) & & 1(Ref) & \\
\hline Yes $(\mathrm{N}=432)$ & $20(4.6)$ & $1.34(0.81-2.22)$ & 0.259 & $1.35(0.81-2.24)$ & 0.253 \\
\hline \multicolumn{6}{|l|}{ girl } \\
\hline No $(N=1965)$ & $67(3.4)$ & 1 (Ref) & & 1(Ref) & \\
\hline Yes(N=384) & $22(5.7)$ & $1.72(1.05-2.82)$ & 0.031 & $1.68(1.02-2.78)$ & 0.042 \\
\hline \multicolumn{6}{|l|}{ a Model 1: Unadjusted; } \\
\hline
\end{tabular}

\section{Association Between Sleep Problems And Allergic Rhinitis}

Among participants diagnosed having allergic rhinitis, 41 (8.0\%) had short sleep duration, $120(23.1 \%)$ had a late bedtime, and 116 (22.7\%) had frequent nocturnal awakenings, respectively; while among participants without allergic rhinitis, 251 (5.8\%) had short sleep duration, $856(19.7 \%)$ had a late bedtime, and 700 (16.1\%) had frequent nocturnal awakenings, respectively. Significant associations of short sleep duration, late bedtime and frequent nocturnal awakenings with allergic rhinitis were found (Table 2 and Model 1 in Table 3). However, significant association was only found between frequent nocturnal awakenings and allergic rhinitis after adjusted for potential confounders (Table 3). In the fully adjusted model (Model 4), the adjusted OR for allergic rhinitis for frequent nocturnal awakenings was $1.59(95 \% \mathrm{Cl}: 1.27-1.99)$. And the association between frequent nocturnal awakenings and allergic rhinitis was found both in boys and girls. (Table 5).

Table 5

Association between frequent nocturnal awaking and allergic rhinitis according to gender

\begin{tabular}{|c|c|c|c|c|c|}
\hline \multirow[t]{2}{*}{ Frequent Nocturnal awaking } & \multirow[t]{2}{*}{ No. of allergic rhinitis } & Model $1^{a}$ & \multirow[t]{2}{*}{$P$} & Model $2^{b}$ & \multirow[t]{2}{*}{$P$} \\
\hline & & OR $(95 \% \mathrm{Cl})$ & & OR $(95 \% \mathrm{Cl})$ & \\
\hline \multicolumn{6}{|l|}{ boy } \\
\hline No $(N=2086)$ & 232(11.1) & 1 (Ref) & & 1 (Ref) & \\
\hline Yes $(\mathrm{N}=432)$ & $68(15.7)$ & $1.49(1.11-2.00)$ & 0.007 & $1.57(1.17-2.12)$ & 0.003 \\
\hline \multicolumn{6}{|l|}{ girl } \\
\hline No $(N=1965)$ & 163(8.3) & 1 (Ref) & & 1 (Ref) & \\
\hline Yes $(\mathrm{N}=384)$ & $48(12.5)$ & $1.58(1.12-2.22)$ & 0.009 & $1.73(1.15-2.30)$ & 0.006 \\
\hline \multicolumn{6}{|l|}{ a Model 1: Unadjusted; } \\
\hline $\begin{array}{l}\text { b Model 2: Adjusted for regio } \\
\text { tobacco exposure during pre }\end{array}$ & $\begin{array}{l}\text { ler, age, mother's educat } \\
\text { feeding pattern before }\end{array}$ & $\begin{array}{l}\text { level, BMI z-score } \\
\text { nths. }\end{array}$ & ery $m$ & birth weight, ma & \\
\hline
\end{tabular}

\section{Discussion}

In this study, we used a representative citywide survey data, which was part of the NSPGDC, to investigate the association of sleep problems with asthma and allergic rhinitis among children aged 3-6 years in Guangzhou. The results revealed the prevalence of 
asthma and allergic rhinitis among preschool children was $3.7 \%$, and $10.5 \%$ respectively. The findings also suggested that frequent nocturnal awakenings but not short sleep duration and late bedtime, was significant associated with asthma and allergic rhinitis. However, these associations of frequent nocturnal awakenings and asthma differed by gender.

In the present study, we found that the prevalence of asthma and allergic rhinitis among preschool children was consistent with previous studies conducted both in some region and countries. For example, Deng's research in Beijing among preschool children revealed the prevalence of doctor-diagnosed childhood asthma was 2.8\% [24], Pereira et al conducted study in Portuguese children aged 3-5 years demonstrated that the prevalence of physician-diagnosed asthma was $4.6 \%$, and prevalence of physician-diagnosed rhinitis was 11.8\% [25]. Deng and colleague's research in Changsha in China exhibited the prevalence of ever doctor-diagnosed allergic rhinitis was 7.3\% [26]. Although Bloom's research in UK showed the prevalence of preschool wheeze requiring attendance to a physician in 2017 was $7.7 \%$, but only one fifth of the received an asthma diagnosis[27]. However, our results was lower than the average prevalence of six representative cities in China, which showed the prevalence of asthma and allergic rhinitis among preschool children were $8.0 \%$ and $16.6 \%$, respectively [28] As the regional difference, the prevalence of asthma and allergic rhinitis was variant in different regions, and our result was consisted with the Urumqi's prevalence, with $3.5 \%$ and $10.9 \%$ respectively [28]. The discrepancies among researches might be related to different characteristics of study participants (residence, ethnicity) apart from the different measurements for asthma and allergic rhinitis. Besides, the under-diagnosis although with symptom may underestimated the prevalence of asthma and allergic rhinitis [27].

Our findings suggest that frequent nocturnal awakening was associated with asthma $(\mathrm{OR}=1.49,1.05-2.13)$ and allergic rhinitis $(\mathrm{OR}=1.59,1.27-1.99)$, which were similar to previous studies that investigated the association of sleep problems with allergic diseases among children and adolescent $[9,10,29]$. Wang et al conducted a study to examine the associations of sleep disorders with the risk of wheeze and allergic rhinitis among 566 Chine toddlers and found that having more than 2 times of nocturnal awaking per night was associated with a higher risk of wheeze $(\mathrm{OR}=6.16,1.28 \sim 29.74)$ [9]. Kozyrskyj et al analyzed the conditions of 2398 children from on a community-based birth cohort in Australia and found that persistent nocturnal awakening before 3 years of age was associated with an increased risk of non-atopic asthma at age $6(\mathrm{OR}=1.87,1.08$ 3.25), after adjusting for other risk factors of asthma, including co-sleeping, wheeze and family stress [10]. Jernelöv et al present data from a longitudinal study showing that children's overtired at the age of 8 years increases the risk of rhinitis symptoms at age 13 [29].

The association between frequent nocturnal awaking and asthma and allergic rhinitis could be explained from two aspects. On one hand, the nocturnal awaking may be consequence of asthma or allergic rhinitis, as the airway inflammation and congestion or the nasal obstruction, may cause them to wake up frequently. There were increasing evidence among children showed the high prevalence of nocturnal awakening caused by asthma or allergic rhinitis [30-32]. On the other hand, the frequent nocturnal awaking may be a risk factor for asthma or allergic rhinitis, which was demonstrated in a longitudinal study [10]. The possible biological mechanism was as follow: first, frequent nocturnal awakening may increase the levels of pro-inflammatory cytokines and decrease the immunologic tolerance to allergen $[9,10]$, shifting the balance between Th1 and Th2 cytokines towards an allergy related (Th2) pattern [29], which are known factors contributing to allergic diseases such as asthma and allergic rhinitis. Second, frequent nocturnal awakening could disrupt the regulation of the hypothalamic-pituitary-adrenal (HPA) axis [33, 34] and the circadian rhythms of melatonin [35,36], which showed blunted cortisol awakening response and lower cortisol levels and a decline in the level of melatonin [33,34], and increase the risk of asthma and rhinitis [37-40]. In summary, the association between frequent nocturnal awakening and asthma and allergic rhinitis might work in both direction. However, as our study is a cross-sectional study, we can't ascribe causality of the association of frequent nocturnal awaking and asthma and allergic rhinitis, further research to address the causal relationship between sleep problems and allergic diseases seem warranted.

In this study, we also found that the associations of frequent nocturnal awakening with asthma was differed by gender, and the association was found only in girls. There was few study detecting the gender difference of association between sleep problems and allergic disease among preschooler in general population. And our result was consisted with the research on asthma patient. For example, Strunk's research on asthma patients in children showed that night awakening caused by asthma was marginally less for males than females [30], Goldstein and colleagues' research among 2-15 years old children revealed that the association of asthma with sleep-disordered breathing was found only in girls [41]. The gender differences may be driven by hormonal effect on school-age children [42]. However, it is noticed that the sex difference of sex hormonal will not be significant, until the onset of puberty [43]. So, whether the explanation can applied to preschoolers still need to verify by the further studies. 


\section{Strengths And Limitations}

For this citywide cross-sectional study, we recruited 4867 representative participants from rural and urban Guangzhou by using a well-designed protocol, which makes our results more generalized. In the analysis we have adjusted for several important confounders, such as region and maternal tobacco exposures during pregnancy, which was not adjusted in previous studies, making our results more robust. Additionally, there were few study explored the association of sleep problems with asthma and allergic rhinitis among Chinese preschool children in a large sample size, and there was no study explored the gender difference of the association in general population, which will enrich the research in this area.

There were several limitations in our study. First, asthma and allergic rhinitis were not determined by objective measures, but rather parent reported symptom from ISAACQ and previous diagnosis, which although was highly recognized for its reliability and validity and was used in previous studies [10, 29,44]. Second, sleep problems were assessed through questionnaires based on the parents' reports, instead of objective measurement, thus recall bias may exist. On balance, previous studies have demonstrated that information regarding sleep garnered from parents is likely to be reliable [45]. Third, although we have adjusted for various potential confounders, we did not adjust for family allergy history of the parents or mother's stress during pregnancy, which are risk factors for allergenic diseases [10]. Fourth, this study is a cross-sectional study, which deduces a weak association in the exploration of the causal relationship of sleep problems and asthma and allergic rhinitis. Future prospective research studies are needed to validate these findings, since asthma and allergic rhinitis are significant clinical and public concerns.

Sleep problems including shortened sleep duration, late bedtime and frequent nocturnal awaking are common among children, which have a broad impact on children's development and physical health. In the present study, we used data from the NSPGDC to investigate the association of sleep problems with asthma and allergic rhinitis among Chinese preschool children and found that frequent nocturnal awakening was associated with asthma and allergic rhinitis, and the association of frequent nocturnal awakening with asthma differed by gender. The results suggests that pediatricians should consider evaluating sleep problems when evaluating the consequence or risk factors for asthma and allergic rhinitis, and that parents should help their children developing good sleeping habits to reduce the risk of asthma and allergic rhinitis.

\section{Conclusions}

Findings from this well representative study suggested that frequent nocturnal awakening was associated with asthma and allergic rhinitis, and the association of frequent nocturnal awakening with asthma differed by gender. Further studies are warranted to address the causal relationship between nocturnal awaking and asthma and allergic rhinitis.

\section{List Of Abbreviations}

ARDs: Allergic respiratory diseases

BMI: Body mass index

Cl: Confidence intervals

NSPGDC: National Survey on Physical Growth and Development of Children in nine cities of China

OR: Odds ratio

\section{Declarations}

Data Availability Data and material of this study could be available through contacting with the corresponding authors. Data of NSPGDC can't be available because its' intellectual property belongs to Guangzhou Health and Family Planning Commission.

Acknowledgment We thank the participating families, community health workers of NSPGDC study. We also express our gratitude to Dr Weiju Zhou, Faculty of Education, health and well-being, University of Wolverhampton, for his efforts on editing and comments on this manuscript.

Page 10/13 
Authors' contribution YM participated in the conceptualization of this study, acquisition of data, statistical analyses and drafted the main manuscript. JT participated in the statistical analyses and interpretation analyses and review the manuscript.

YQW: participated in the statistical analyses and interpretation analyses and revised the manuscript. YH: participated in the acquisition of data and statistical analyses. JJL participated in data clean and interpretation analyses. LJ and YFX participated in investigation, entering data and review the manuscript. YYS participated in the acquisition of data.

Funding This study was supported by grant of Guangzhou Municipal Health Commission (Grant No. 20191A011029). The funder had no role in study design, data collection, data analysis, data interpretation, or writing the report.

Competing interests: The authors declare that they have no competing interests.

\section{References}

1. Valero, A., Quirce, S., Dávila, I. \& Delgado, J. Domínguez-Ortega, J. Allergic respiratory disease: different allergens, different symptoms. Allergy, 72 (9), 1306-1316 (2017).

2. Asher, M. I. et al. Worldwide time trends in the prevalence of symptoms of asthma, allergic rhinoconjunctivitis, and eczema in childhood: ISAAC Phases One and Three repeat multicountry cross-sectional surveys. Lancet, 368 (9537), 733-43 (2006).

3. Korea Centers for Disease Control and Prevention. The Statistics of the 8th Korea Youth Risk Behavior Web-based Survey (KYRBWS) in 2012. http://yhs.cdc.go.kr/. Accessed 07 March 2021(2012)

4. Huang, C. et al. Updated prevalences of asthma, allergy, and airway symptoms, and a systematic review of trends over time for childhood asthma in Shanghai, China. PLoS One, 10 (4), e0121577 https://doi.org/10.1371/journal.pone.0121577 (2015).

5. Linneberg, A. et al. Burden of allergic respiratory disease: a systematic review. Clin Mol Allergy, 14, 12 (2016).

6. Wang, X. D. et al. An increased prevalence of self-reported allergic rhinitis in major Chinese cities from 2005 to 2011 . Allergy, 71 (8), 1170-1180 (2016).

7. Gilles, S. et al. The role of environmental factors in allergy: A critical reappraisal. Exp Dermatol, 27 (11), 1193-1200 (2018).

8. Owens, J. Classification and epidemiology of childhood sleep disorders. Prim Care, 35 (3), 533-46 (2008).

9. Wang, X. et al. Sleep disorders and allergic diseases in Chinese toddlers. Sleep Med, 37, 174-179 (2017).

10. Kozyrskyj, A. L., Kendall, G. E., Zubrick, S. R., Newnham, J. P. \& Sly, P. D. Frequent nocturnal awakening in early life is associated with nonatopic asthma in children. Eur Respir J, 34 (6), 1288-95 (2009).

11. Nilsson, L., Castor, O., Löfman, O., Magnusson, A. \& Kjellman, N. I. Allergic disease in teenagers in relation to urban or rural residence at various stages of childhood. Allergy, 54 (7), 716-21 (1999).

12. Vardavas, C. I. et al. The independent role of prenatal and postnatal exposure to active and passive smoking on the development of early wheeze in children. Eur Respir J, 48 (1), 115-24 (2016).

13. Zhou, Y. et al. Maternal tobacco exposure during pregnancy and allergic rhinitis in offspring: A systematic review and metaanalysis. Med. (Baltim), 100 (34), e26986 (2021).

14. Hill, D. L. et al. Immune system development varies according to age, location, and anemia in African children. Sci Trans/ Med, 12 (529), eaaw9522 (2020).

15. Capital Institute of Pediatrics. The Coordinating Study Group of Nine Cities on the Physical Growth and Development of Children. A national survey on physical growth and development of children under seven years of age in nine cities of China in 2015. Zhonghua Er Ke Za Zhi, 56 (3), 192-199 (2018).

16. Zong, X. N., Li, H. \& Zhu, Z. H. Secular Trends in Height and Weight for Healthy Han Children Aged 0-7 Years in China, 19752005. Am J Hum Biol, 23 (2), 209-15 (2011).

17. Ye, W. Cluster random sampling in population survey. Renkou Yanjiu, 29 (6), 51 (1983).

18. Li, H. et al. Body mass index cut-offs for overweight and obesity in Chinese children and adolescents aged 2-18 years. Chin J Epidemiol, 31 (6), 616-620 (2013).

19. National Sleep Foundation. Sleep in America Poll 2004. Available from: https://www.sleepfoundation.org/professionals/sleepamerica-polls/2004-children-and-sleep 
20. Li, S. H. et al. Development and psychometric properties of the Chinese version of children's sleep habits questionnaire. Chin J Pediatr, 45 (3), 176-180 (2007).

21. Hirshkowitz, M. et al. National Sleep Foundation's updated sleep duration recommendations: final report. Sleep Health, 1 (4), 233-243 (2015).

22. Yao, T. C. et al. PATCH Study Group. Associations of age, gender, and BMI with prevalence of allergic diseases in children: PATCH study. J Asthma, 48 (5), 503-10 (2011).

23. Bisanti, L. et al. Respiratory and allergic disorders in children: differences in socio-economic status. Epidemiol Prev, 29, 32-5 (2005).

24. Deng, X. et al. Factors Associated With Childhood Asthma and Wheeze in Chinese Preschool-Aged Children. Front Med (Lausanne), 8, 742581 (2021).

25. Pereira, A. M. et al. Severity of rhinitis and wheezing is strongly associated in preschoolers: A population-based study. Pediatr Allergy Immunol, 26 (7), 618-27 (2015).

26. Deng, Q. et al. Early life exposure to traffic-related air pollution and allergic rhinitis in preschool children. Respir Med, 121, 67-73 (2016).

27. Bloom, C. I., Franklin, C., Bush, A., Saglani, S. \& Quint, J. K. Burden of preschool wheeze and progression to asthma in the UK: Population-based cohort 2007 to 2017. J Allergy Clin Immunol, 147 (5), 1949-1958 (2021).

28. Chen, F. et al. The effects of $\mathrm{PM}_{2.5}$ on asthmatic and allergic diseases or symptoms in preschool children of six Chinese cities, based on China, Children, Homes and Health (CCHH) project. Environ Pollut, 232, 329-337 (2018).

29. Jernelöv, S., Lekander, M., Almqvist, C., Axelsson, J. \& Larsson, H. Development of atopic disease and disturbed sleep in childhood and adolescence-a longitudinal population-based study. Clin Exp Allergy, 43 (5), 552-9 (2013).

30. Strunk, R. C., Sternberg, A. L., Bacharier, L. B. \& Szefler, S. J. Nocturnal awakening caused by asthma in children with mild-tomoderate asthma in the childhood asthma management program. J Allergy Clin Immunol, 110 (3), 395-403 (2002).

31. de Jong, C. C. M. et al. Diagnosis of asthma in children: the contribution of a detailed history and test results. Eur Respir J, 54 (6), $1901326(2019)$.

32. Leger, D., Bonnefoy, B., Pigearias, B., de La Giclais, B. \& Chartier, A. Poor sleep is highly associated with house dust mite allergic rhinitis in adults and children. Allergy Asthma Clin Immunol, 13, 36 (2017).

33. Tsai, J. C., Chou, K. R., Tsai, H. T., Yen, Y. C. \& Niu, S. F. Effects of Nocturnal Sleep Quality on Diurnal Cortisol Profiles and Attention in Nurses: A Cross-Sectional Study. Biol Res Nurs, 21 (5), 510-518 (2019).

34. Vargas, I. \& Lopez-Duran, N. The cortisol awakening response after sleep deprivation: Is the cortisol awakening response a "response" to awakening or a circadian process? J Health Psychol. ; 25 (7), 900-912 (2020).

35. Kohyama, J. Late nocturnal sleep onset impairs a melatonin shower in young children. Neuro Endocrinol Lett, 23 (5-6), 385-6 (2002).

36. Huang, C. T., Chiang, R. P., Chen, C. L. \& Tsai, Y. J. Sleep deprivation aggravates median nerve injury-induced neuropathic pain and enhances microglial activation by suppressing melatonin secretion. Sleep, 37 (9), 1513-23 (2014).

37. Fidan, V. et al. C.Variance of melatonin and cortisol rhythm in patients with allergic rhinitis. Am J Otolaryngol, 34 (5), 416-9 (2013).

38. Kroll, J. L., Brown, E. S. \& Ritz, T. Cortisol awakening response and fractional exhaled nitric oxide in asthma. Clin Exp Allergy, 49 (8), 1150-1153 (2019).

39. Lebold, K. M., Jacoby, D. B. \& Drake, M. G. Inflammatory mechanisms linking maternal and childhood asthma. J Leukoc Biol, 108 (1), 113-121 (2020).

40. Tufvesson, E., Aronsson, D., Ankerst, J., George, S. C. \& Bjermer, L. Peripheral nitric oxide is increased in rhinitic patients with asthma compared to bronchial hyperresponsiveness. Respir Med, 101 (11), 2321-6 (2007).

41. Goldstein, N. A. et al. The prevalence of sleep-disordered breathing in children with asthma and its behavioral effects. Pediatr Pulmonol, 50 (11), 1128-36 (2015).

42. Santos, C., Moreira, G., Togeiro, S. M. \& Tufik, S. Gender and asthma-severity differences in sleep disordered breathing in children with asthma. Pediatr Pulmonol, 51 (1), 89-90 (2016).

Page $12 / 13$ 
43. Elmlinger, M. W., Kühnel, W. \& Ranke, M. B. Reference ranges for serum concentrations of lutropin (LH), follitropin (FSH), estradiol (E2), prolactin, progesterone, sex hormone-binding globulin (SHBG), dehydroepiandrosterone sulfate (DHEAS), cortisol and ferritin in neonates, children and young adults. Clin Chem Lab Med, 40 (11), 1151-60 (2002).

44. The International Study of Asthma and Allergies in Childhood (ISAAC). Steering Committee. Worldwide variation in prevalence of symptoms of asthma, allergic rhino conjunctivitis, and atopic eczema: ISAAC. The International Study of Asthma and Allergies in Childhood (ISAAC) Steering Committee. Lancet, 351 (9111), 1225-32 (1998).

45. Hestetun, I., Svendsen, M. V. \& Oellingrath, I. M. Sleep problems and mental health among young Norwegian adolescents. Nord J Psychiatry, 72 (8), 578-585 (2018). 